\title{
Synthesis and biological activity of a new class of sulfone linked bis(heterocycles)
}

\author{
Venkatapuram Padmavathi,* Konda Mahesh, Dandu Rangayapalle Chinna Venkata \\ Subbaiah, Duvvuru Deepti, and Gali Sudhakar Reddy
}

Department of Chemistry, Sri Venkateswara University, Tirupati 517 502, Andhra Pradesh, India

E-mail:vkpuram2001@yahoo.com

\begin{abstract}
Novel sulfone linked bis(heterocycles) having two different heterocyclic rings viz., oxazoline / thiazoline in combination with pyrrole are prepared from $E$-aroylethenesulfonylacetic acid methyl ester exploiting ester and olefin functionalities. The compounds having pyrrole and thiazoline rings exhibited greater antimicrobial activity.
\end{abstract}

Keywords: 2-Oxazolines, 2-thiazolines, $\mathrm{SmCl}_{3}$, pyrrole, tosylmethyl isocyanide

\section{Introduction}

The chemistry of heterocyclic compounds has attracted attention in recent times due to its increasing importance in the field of pharmaceuticals and industries. In fact, the development of simple, elegant and facile methodologies for the synthesis of five membered heterocycles is one of the important aspects in organic synthesis. Among five membered heterocycles, pyrroles, oxazoles and thiazoles have gained attention because of their varied physiological activities. 4Aminopyrrole-2-carboxylate exhibits antibiotic, antiviral and oncolytic activities. ${ }^{1}$ Several 2oxazolines have been used as therapeutic agents. Because of their structural relationship to procaine, the aminophenyl-2-oxazolines have local anaesthetic properties and at the same time have a lower toxicity than procaine. ${ }^{2}$ Besides, the oxazoline and thiazoline rings are important constituents of bioactive natural products and pharmaceuticals. ${ }^{3}$ The use of oxazoline and thiazoline rings as building blocks in pharmaceutical drug discovery is continually increasing. Hence, it is thought that a worthwhile programme would be to prepare molecules having both pyrrole and oxazole / thiazole rings. Multistep synthetic routes for 3,4-disubstituted pyrroles have been reported in the literature either by coupling of imines and nitroalkanes or using Friedel-Crafts acylation with an electron withdrawing group on the pyrrole nitrogen or 3,4silylated precursors. ${ }^{4}$ However, these synthetic routes are often complicated and limited to only 
some substituents. 3,4-Disubstitued pyrroles have also been synthesized from Michael acceptors with tosylmethyl isocyanide (TosMIC). ${ }^{5,6}$ A variety of methods have been reported for the synthesis of oxazolines viz., cyclodehydration of amidoalcohols, ${ }^{7}$ condensation of imidate hydrochlorides, ${ }^{8}$ carboxylic acids, ${ }^{9}$ orthoesters,${ }^{10}$ imino ether hydrochlorides, ${ }^{11}$ and nitriles ${ }^{12}$ with aminoalcohols. Similarly, syntheses of thiazolines are reported by the coupling of imidate esters with 2-aminothiols, ${ }^{13}$ cyclodehydration of hydroxy thioamides ${ }^{14}$ and heterocyclic inter conversions from oxazolines ${ }^{15}$ or oxazolidines. ${ }^{16}$ However, lanthanide amino alkoxide complexes as reagents for the preparation of oxazolines and thiazolines are sparsely reported ${ }^{17}$ Herein we wish to report our results pertaining to the development of bis heterocycles from aroylethenesulfonylacetic acid methyl ester by exploiting ester moiety using lanthanide 2aminoalkoxide complexes to get 2-oxazolines and 2-thiazolines and olefin moiety using 1,3dipolar cycloaddition of TosMIC to develop pyrrole unit.

\section{Results and Discussion}

The synthetic intermediate aroylethenesulfonylacetic acid methyl ester (4) is prepared by the condensation of 1-aroyl-2-chloroethene (1) with mercaptoacetic acid followed by oxidation and esterification (Scheme 1) Treatment of $\mathbf{4}$ with 2-aminoethanol in the presence of $n$-butyllithium complexed with a suspension of 5-10\% mol. equiv. of anhydrous $\mathrm{SmCl}_{3}$ in toluene produced 2(aroylethenesulfonylmethyl)-4,5-dihydrooxazole (5) (Scheme1). Adopting similar methodology, the reaction of $\mathbf{4}$ is carried out with 2-aminoethanethiol and $n$-butyllithium in the presence of anhydrous $\mathrm{SmCl}_{3}$ in toluene. The compound obtained is found to be 2(aroylethenesulfonylmethyl)-4,5-dihydrothiazole (6) (Scheme 1). The ${ }^{1} \mathrm{H}-\mathrm{NMR}$ spectra of 5a and 6a displayed two triplets for $\mathrm{C}_{4}-\mathrm{H}$ and $\mathrm{C}_{5}-\mathrm{H}$ of 2-oxazoline and 2-thiazoline rings at $\delta 3.78,4.88$ and 3.91, 3.38. Besides, two doublets and a singlet are observed at $\delta 7.96,7.62$ and 4.29 in $\mathbf{5 a}$ and at $\delta 7.89,7.61$ and 4.23 in $\mathbf{6 a}$ which are assigned to olefin protons $\mathrm{H}_{\mathrm{A}}, \mathrm{H}_{\mathrm{B}}$ and methylene protons, respectively. The $J$ value $(J=14.4,14.4 \mathrm{~Hz})$ indicates that $\mathrm{H}_{\mathrm{A}}$ and $\mathrm{H}_{\mathrm{B}}$ possess trans geometry. The ${ }^{13} \mathrm{C}-\mathrm{NMR}$ spectrum of 5a displayed signals at $52.4(\mathrm{C}-4), 57.8(\mathrm{C}-5), 55.2\left(\mathrm{SO}_{2}\right.$ $\left.\mathrm{CH}_{2}\right), 137.1(\mathrm{CO}-\mathrm{CH}), 144.4\left(\mathrm{CH}-\mathrm{SO}_{2}\right), 158.9(\mathrm{C}-2), 182.4(\mathrm{C}=\mathrm{O})$ where as $6 \mathbf{a}$ at $37.8(\mathrm{C}-5)$, $54.2(\mathrm{C}-4), 56.8\left(\mathrm{SO}_{2}-\mathrm{CH}_{2}\right), 136.8(\mathrm{CO}-\mathrm{CH}), 143.9\left(\mathrm{CH}-\mathrm{SO}_{2}\right), 162.3(\mathrm{C}-2), 181.7(\mathrm{C}=\mathrm{O})$ besides signals due to aromatic carbons. 


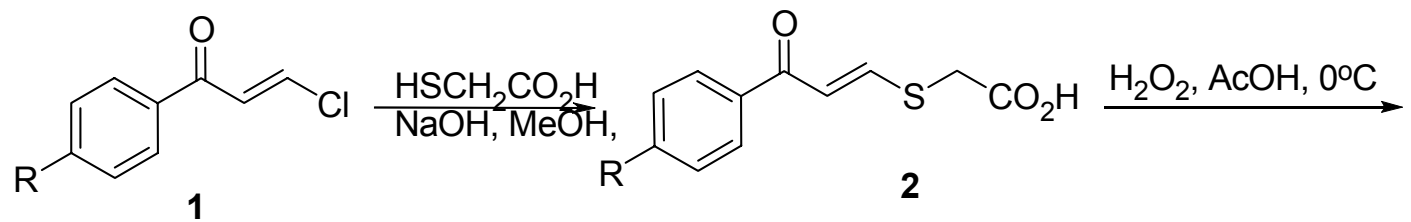

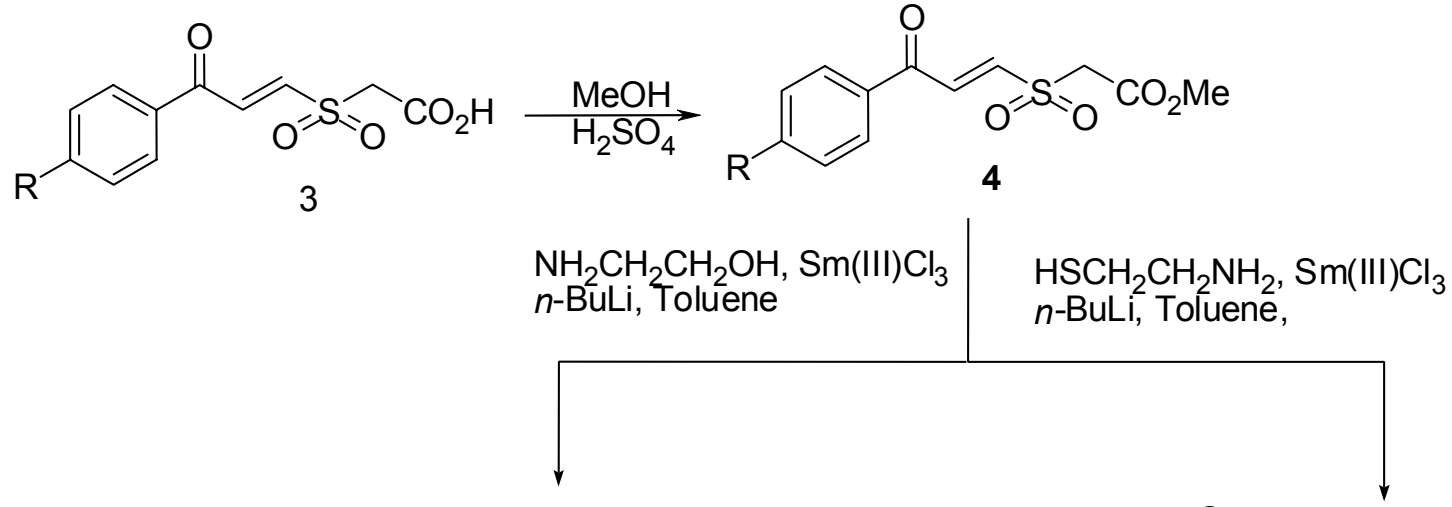<smiles>[R]c1ccc(C(=O)/C=C/S(=O)(=O)Cc2ncco2)cc1</smiles>
$\mid \begin{aligned} & \text { TosMIC, NaH, } \\ & \mathrm{Et}_{2} \mathrm{O}+\mathrm{DMSO}\end{aligned}$<smiles>[R]c1ccc(C(=O)/C=C/S(=O)(=O)Cc2nccs2)cc1</smiles>
$\mathbf{6}$
$\mathrm{Et}_{2} \mathrm{O}+\mathrm{DMSO}$<smiles>[R]c1ccc(C(=O)c2c[nH]cc2S(=O)(=O)Cc2ncco2)cc1</smiles><smiles>[R]c1ccc(C(=O)c2c[nH]cc2S(=O)(=O)Cc2nccs2)cc1</smiles>
a: $\mathrm{R}=\mathrm{H}$
$\mathrm{b}: \mathrm{R}=4-\mathrm{Me}$
c: $\mathrm{R}=4-\mathrm{Cl}$

\section{Scheme 1}

The olefin moiety present in $\mathbf{5}$ and $\mathbf{6}$ is utilized to develop pyrrole ring. The reaction of $\mathbf{5}$ with tosylmethyl isocyanide in the presence of sodium hydride in a mixture of ether and dimethyl sulfoxide gave a solid which is identified as 2-(4'-aroyl-1'H-pyrrol-3'-sulfonylmethyl)4,5-dihydrooxazole (7). Similarly treatment of 6 with tosylmethyl isocyanide in the presence of sodium hydride furnished 2-(4'-aroyl-1' H-pyrrol-3'-sulfonylmethyl)-4,5-dihydrothiazole (8) (see Scheme 1). The ${ }^{1} \mathrm{H}-\mathrm{NMR}$ spectra of $7 \mathbf{a}$ and 8a exhibited two singlets at $\delta 6.48,6.56$ and 6.96, 6.78 which are assigned to $\mathrm{C}_{2}{ }^{\prime}-\mathrm{H}$ and $\mathrm{C}_{5}{ }^{\prime}-\mathrm{H}$ of pyrrole ring. Apart from these two triplets are observed at $\delta 3.73,4.94(\mathbf{7 a})$ and at 3.95, $3.36(\mathbf{8 a})$ due to $\mathrm{C}_{4}-\mathrm{H}$ and $\mathrm{C}_{5}-\mathrm{H}$ of oxazoline and 
thiazoline rings. A sharp singlet is observed at 4.21 (7a) and 4.17 (8a) for methylene protons. Besides a broad singlet is appeared at 9.21 (7a) and 9.13 (8a) for $\mathrm{NH}$ which disappeared on deuteration. The ${ }^{13} \mathrm{C}-\mathrm{NMR}$ spectra of $7 \mathbf{a}$ and $\mathbf{8 a}$ displayed signals at $52.4(\mathrm{C}-4), 58.2(\mathrm{C}-5), 55.9$ $\left(\mathrm{SO}_{2}-\mathrm{CH}_{2}\right), 102.4\left(\mathrm{C}-4^{\prime}\right), 105.2\left(\mathrm{C}-3^{\prime}\right), 116.8\left(\mathrm{C}-2^{\prime}\right), 119.6\left(\mathrm{C}-5^{\prime}\right), 159.7(\mathrm{C}-2), 180.2(\mathrm{C}=\mathrm{O})$ and at $37.4(\mathrm{C}-5), 53.2(\mathrm{C}-4), 56.6\left(\mathrm{SO}_{2}-\mathrm{CH}_{2}\right), 103.6\left(\mathrm{C}-4^{\prime}\right), 104.8\left(\mathrm{C}-3^{\prime}\right), 115.1\left(\mathrm{C}-2^{\prime}\right), 119.8\left(\mathrm{C}-5^{\prime}\right)$, $163.3(\mathrm{C}-2), 181.1(\mathrm{C}=\mathrm{O})$.

Biological evaluation - Antimicrobial activity. The compounds 5-8 were tested for antimicrobial activity at two different concentrations: 100 and $200 \mu \mathrm{g} / \mathrm{mL}$. The antibacterial activity was screened against Staphylococcus aureus, Bacillus subtilis (Gram-positive bacteria) and Escherichia coli, Klebsiella pneumoniae (Gram-negative bacteria) on nutrient agar plates at $37^{\circ} \mathrm{C}$ for $24 \mathrm{~h}$ using chloramphenicol (25 $\mu \mathrm{g}$ per disc) as reference drug. The compounds were also evaluated for their antifungal activity against Fusarium solani, Curvularia lunata and Aspergillus niger using ketoconazole ( $25 \mu \mathrm{g}$ per disc) as standard drug. Fungi cultures were grown on potato dextrose agar medium (PDA) at $25{ }^{\circ} \mathrm{C}$ for 3 days. The spore suspension was adjusted to $10^{6}$ pores $\mathrm{ml}^{-1}$ at an $\mathrm{mg} \mathrm{ml}^{-1}$ concentration by the Vincent and Vincent method. ${ }^{18}$ The results of the compounds of preliminary antibacterial testing shown in Table 1 revealed that, in general, the inhibitory activity against the Gram-positive bacteria was higher than that of the Gram-negative bacteria. The compounds 6c, 8a and 8c showed excellent activity against Grampositive bacteria (inhibitory zone $>25 \mathrm{~mm}$ ) and good activity against Gram-negative bacteria (inhibitory zone $>18 \mathrm{~mm}$ ). The compounds $\mathbf{5}$ and $\mathbf{7}$ displayed least activity against both bacteria. All the test compounds exhibited moderate (5a-c and 7a-c) to high (6a-c and 8a-c) inhibitory effect towards tested fungi (Table 2).

Table 1. Antibacterial activity of compounds 5-8

\begin{tabular}{|c|c|c|c|c|c|}
\hline \multirow{3}{*}{ Compound } & \multirow{3}{*}{$\begin{array}{c}\text { Concentration } \\
(\mu \mathrm{g})\end{array}$} & \multicolumn{4}{|c|}{ Zone of inhibition (mm) } \\
\hline & & \multicolumn{2}{|c|}{ Gram-positive bacteria } & \multicolumn{2}{|c|}{ Gram-negative bacteria } \\
\hline & & S. aureus & B. subtilis & E. coli & K. pneumoniae \\
\hline \multirow[t]{2}{*}{$5 \mathbf{a}$} & 100 & 10 & 9 & - & - \\
\hline & 200 & 12 & 12 & - & - \\
\hline \multirow[t]{2}{*}{$5 \mathbf{b}$} & 100 & 9 & 9 & - & - \\
\hline & 200 & 11 & 10 & - & - \\
\hline \multirow[t]{2}{*}{$5 c$} & 100 & 12 & 10 & 9 & 8 \\
\hline & 200 & 15 & 14 & 11 & 9 \\
\hline \multirow[t]{2}{*}{ 6a } & 100 & 22 & 25 & 16 & 16 \\
\hline & 200 & 26 & 27 & 20 & 19 \\
\hline
\end{tabular}




\begin{tabular}{|c|c|c|c|c|c|}
\hline \multirow[t]{2}{*}{$6 b$} & 100 & 19 & 18 & 13 & 11 \\
\hline & 200 & 22 & 23 & 16 & 15 \\
\hline \multirow[t]{2}{*}{$6 c$} & 100 & 23 & 22 & 19 & 20 \\
\hline & 200 & 27 & 26 & 23 & 24 \\
\hline \multirow[t]{2}{*}{$7 \mathbf{a}$} & 100 & 12 & 11 & 9 & 8 \\
\hline & 200 & 15 & 13 & 11 & 11 \\
\hline \multirow[t]{2}{*}{$7 b$} & 100 & 9 & 11 & - & - \\
\hline & 200 & 13 & 14 & - & - \\
\hline \multirow[t]{2}{*}{ 7c } & 100 & 11 & 12 & 11 & 9 \\
\hline & 200 & 15 & 15 & 13 & 11 \\
\hline \multirow[t]{2}{*}{$8 \mathbf{a}$} & 100 & 25 & 27 & 19 & 20 \\
\hline & 200 & 29 & 30 & 25 & 25 \\
\hline \multirow[t]{2}{*}{$8 b$} & 100 & 20 & 19 & 17 & 14 \\
\hline & 200 & 24 & 25 & 20 & 20 \\
\hline \multirow[t]{2}{*}{$8 c$} & 100 & 30 & 29 & 22 & 23 \\
\hline & 200 & 32 & 33 & 26 & 25 \\
\hline \multirow[t]{2}{*}{ Chloramphenicol } & 100 & 35 & 38 & 40 & 42 \\
\hline & 200 & 39 & 41 & 44 & 45 \\
\hline
\end{tabular}

Table 2. Antifungal activity of compounds 5-8

\begin{tabular}{|c|c|c|c|c|}
\hline \multirow[t]{2}{*}{ Compound } & \multirow{2}{*}{$\begin{array}{c}\text { Concentration } \\
(\mu \mathrm{g})\end{array}$} & \multicolumn{3}{|c|}{ Zone of inhibition $(\mathrm{mm})$} \\
\hline & & F. solani & C. lunata & A. niger \\
\hline \multirow[t]{2}{*}{$5 a$} & 100 & 16 & 16 & 17 \\
\hline & 200 & 20 & 18 & 21 \\
\hline \multirow[t]{2}{*}{$5 b$} & 100 & 17 & 17 & 16 \\
\hline & 200 & 19 & 21 & 21 \\
\hline \multirow[t]{2}{*}{$5 c$} & 100 & 15 & 17 & 15 \\
\hline & 200 & 18 & 20 & 18 \\
\hline
\end{tabular}




\begin{tabular}{|c|c|c|c|c|}
\hline \multirow[t]{2}{*}{$\mathbf{6 a}$} & 100 & 25 & 26 & 25 \\
\hline & 200 & 27 & 28 & 29 \\
\hline \multirow[t]{2}{*}{$\mathbf{6 b}$} & 100 & 24 & 22 & 21 \\
\hline & 200 & 26 & 24 & 24 \\
\hline \multirow[t]{2}{*}{$6 c$} & 100 & 28 & 23 & 26 \\
\hline & 200 & 31 & 25 & 29 \\
\hline \multirow[t]{2}{*}{$7 \mathbf{a}$} & 100 & 19 & 18 & 16 \\
\hline & 200 & 22 & 23 & 20 \\
\hline \multirow[t]{2}{*}{$7 \mathbf{b}$} & 100 & 18 & 17 & 17 \\
\hline & 200 & 20 & 21 & 20 \\
\hline \multirow[t]{2}{*}{$7 c$} & 100 & 20 & 21 & 18 \\
\hline & 200 & 23 & 23 & 20 \\
\hline \multirow{2}{*}{$8 \mathbf{a}$} & 100 & 33 & 33 & 30 \\
\hline & 200 & 36 & 35 & 34 \\
\hline \multirow{2}{*}{$8 b$} & 100 & 29 & 27 & 32 \\
\hline & 200 & 33 & 35 & 36 \\
\hline \multirow{2}{*}{$8 c$} & 100 & 34 & 34 & 33 \\
\hline & 200 & 38 & 40 & 37 \\
\hline \multirow[t]{2}{*}{ Ketoconazole } & 100 & 38 & 41 & 36 \\
\hline & 200 & 42 & 44 & 39 \\
\hline
\end{tabular}

The MIC values were determined as the lowest concentration that completely inhibited visible growth of the microorganisms (Table 3). The structure-antimicrobial activity relationship of the synthesized compounds revealed that the compounds having pyrrole in combination with oxazoline moiety exhibited least activity when compared with compounds having pyrrole with thiazoline moiety. Among the substituents on the aryl group, 4-chloro phenyl derivatives were the most active. The maximum activity was observed with compound $\mathbf{8 c}$. 
Table 3. Minimal inhibitory concentrations (MIC, $\mu \mathrm{g} / \mathrm{mL}$ ) of compounds $\mathbf{6 c}, \mathbf{8 a}$ and 8c

\begin{tabular}{|c|c|c|c|c|c|c|c|}
\hline \multirow[t]{2}{*}{ Compound } & \multicolumn{7}{|c|}{$\begin{array}{l}\text { Minimal inhibitory concentration } \\
(\mathrm{MIC}, \mu \mathrm{g} / \mathrm{mL})\end{array}$} \\
\hline & $\begin{array}{c}S . \\
\text { aureus }\end{array}$ & B. subtilis & E. coli & K. pneumoniae & $\begin{array}{c}F . \\
\text { solani }\end{array}$ & $\begin{array}{c}C . \\
\text { lunata }\end{array}$ & $\begin{array}{l}\text { A. } \\
\text { niger }\end{array}$ \\
\hline 6c & 100 & 200 & 200 & 200 & 100 & 100 & 200 \\
\hline $\mathbf{8 a}$ & 25 & 100 & 100 & 100 & 100 & 100 & 100 \\
\hline $8 c$ & 12.5 & 50 & 50 & 50 & 50 & 12.5 & 25 \\
\hline Chloramphenicol & 6.25 & 6.25 & 6.25 & 12.5 & - & - & - \\
\hline Ketoconazole & - & - & - & - & 12.5 & 6.25 & 6.25 \\
\hline
\end{tabular}

\section{Conclusions}

In conclusion, a new class of bis(heterocycles), pyrrole in combination with oxazoline and thiazoline was developed adopting simple, elegant and well-versed methodologies from a vulnerable substrate, $E$-aroylethenesulfonyl acetic acid methyl ester. The antimicrobial activity of lead compounds showed high inhibitory activity towards fungi than bacteria. The compounds pyrrole in combination with thiazoline displayed greater antimicrobial activity.

\section{Experimental Section}

General Procedures. Melting points were determined in open capillaries on a Mel-Temp apparatus and are uncorrected. The purity of the compounds was checked by TLC (silica gel H, BDH, ethyl acetate-hexane, 1:4). The IR spectra were recorded on a Thermo Nicolet IR 200 FT-IR spectrometer as $\mathrm{KBr}$ pellets and the wave numbers were given in $\mathrm{cm}^{-1}$. The ${ }^{1} \mathrm{H}$ NMR spectra were recorded in $\mathrm{CDCl}_{3} / \mathrm{DMSO}-d_{6}$ on a Jeol JNM $\lambda-300 \mathrm{MHz}$. The ${ }^{13} \mathrm{C}$ NMR spectra were recorded in $\mathrm{CDCl}_{3} / \mathrm{DMSO}-d_{6}$ on a Jeol JNM spectrometer operating at $75.5 \mathrm{MHz}$. All chemical shifts were reported in $\delta$ ( microanalyses were performed on Perkin-Elmer 240C elemental analyzer. The starting compound 1-aroyl-2-chloroethene (1) was prepared by passing vinyl chloride gas into a solution of aroyl chloride in chloroform in the presence of anhydrous $\mathrm{AlCl}_{3}$ at $10-15{ }^{\circ} \mathrm{C} .{ }^{19}$ 
E-Benzoylethenemercaptoacetic acid (2a). Typical procedure. To a solution of sodium hydroxide $(20 \mathrm{mmol})$ in methanol $(10 \mathrm{~mL})$, mercaptoacetic acid $(10 \mathrm{mmol})$ was added dropwise. To this, compound $1(10 \mathrm{mmol})$ was added in portions and the reaction mixture was stirred at 0 ${ }^{\circ} \mathrm{C}$ for $3 \mathrm{~h}$. The contents were poured onto crushed ice and neutralized with dil. HCl. The aqueous layer was extracted with ethyl acetate. The solvent was removed under reduced pressure and the solid obtained was recrystallized from methanol to get 8a. Yield $1.578 \mathrm{~g} \mathrm{(71 \% );} \mathrm{white}$ solid; m. p. $34-36{ }^{\circ} \mathrm{C} ;{ }^{1} \mathrm{H}$ NMR (300 MHz, DMSO- $\left.d_{6}\right): \delta=3.74$ (s, 2H, S- $\mathrm{CH}_{2}$ ), $7.68(\mathrm{~d}, J=13.7$ $\left.\mathrm{Hz}, 1 \mathrm{H}, \mathrm{H}_{\mathrm{B}}\right), 7.93\left(\mathrm{~d}, J=13.7 \mathrm{~Hz}, 1 \mathrm{H}, \mathrm{H}_{\mathrm{A}}\right), 7.46-7.84(\mathrm{~m}, 5 \mathrm{H}, \mathrm{Ar}-\mathrm{H}) ; 9.91(\mathrm{bs}, 1 \mathrm{H}, \mathrm{OH}) ;{ }^{13} \mathrm{C}$ NMR (300 MHz, DMSO- $\left.d_{6}\right): \delta=53.4\left(\mathrm{~S}_{-} \mathrm{CH}_{2}\right), 137.8(\mathrm{CO}-\mathrm{CH}), 143.8(\mathrm{CH}-\mathrm{S}), 171.9(\mathrm{CO}-\mathrm{OH})$, $184.1(\mathrm{C}=\mathrm{O}), 128.7,131.1,132.6,135.5$ (aromatic carbons); IR $(\mathrm{KBr}): v=3200(\mathrm{OH}), 1725$ $(\mathrm{C}=\mathrm{O}), 1660(\mathrm{Ar}-\mathrm{C}=\mathrm{O}), 1585(\mathrm{C}=\mathrm{C})$.

$\boldsymbol{E}$-p-Methylbenzoylethenemercaptoacetic acid (2b). Yield 1.796 g (76\%); white solid; m. p. 45-47 ${ }^{\circ} \mathrm{C} ;{ }^{1} \mathrm{H}$ NMR (300 MHz, DMSO- $\left.d_{6}\right): \delta=2.27\left(\mathrm{~s}, 3 \mathrm{H}, \mathrm{CH}_{3}\right), 3.70\left(\mathrm{~s}, 2 \mathrm{H}, \mathrm{S}-\mathrm{CH}_{2}\right), 7.71(\mathrm{~d}, J$ $\left.=13.9 \mathrm{~Hz}, 1 \mathrm{H}, \mathrm{H}_{\mathrm{B}}\right), 7.95\left(\mathrm{~d}, J=13.9 \mathrm{~Hz}, 1 \mathrm{H}, \mathrm{H}_{\mathrm{A}}\right), 7.38-7.82(\mathrm{~m}, 4 \mathrm{H}, \mathrm{Ar}-\mathrm{H}), 10.1(\mathrm{bs}, 1 \mathrm{H}, \mathrm{OH})$; ${ }^{13} \mathrm{C}$ NMR (300 MHz, DMSO- $\left.d_{6}\right): \delta=23.2\left(-\mathrm{CH}_{3}\right), 53.8\left(\mathrm{~S}_{-} \mathrm{CH}_{2}\right), 137.2(\mathrm{CO}-\mathrm{CH}), 143.3(\mathrm{CH}-\mathrm{S})$, $170.5(\mathrm{COOH}), 183.5(\mathrm{C}=\mathrm{O}), 127.6,130.4,133.1,139.5$ (aromatic carbons); IR (KBr): $v=3214$ $(\mathrm{OH}), 1722(\mathrm{C}=\mathrm{O}), 1657(\mathrm{Ar}-\mathrm{C}=\mathrm{O}), 1581(\mathrm{C}=\mathrm{C})$.

E-p-Chlorobenzoylethenemercaptoacetic acid (2c). Yield 1.899 g (74\%); white solid; m. p. 67-69 ${ }^{\circ} \mathrm{C} ;{ }^{1} \mathrm{H}$ NMR (300 MHz, DMSO- $\left.d_{6}\right): \delta=3.79\left(\mathrm{~s}, 2 \mathrm{H}, \mathrm{S}-\mathrm{CH}_{2}\right), 7.74(\mathrm{~d}, J=13.5 \mathrm{~Hz}, 1 \mathrm{H}$, $\left.\mathrm{H}_{\mathrm{B}}\right), 7.98\left(\mathrm{~d}, J=13.5 \mathrm{~Hz}, 1 \mathrm{H}, \mathrm{H}_{\mathrm{A}}\right), 7.54-7.89(\mathrm{~m}, 4 \mathrm{H}, \mathrm{Ar}-\mathrm{H}), 9.82(\mathrm{bs}, 1 \mathrm{H}, \mathrm{OH}) ;{ }^{13} \mathrm{C}$ NMR $(300$ $\left.\mathrm{MHz}, \mathrm{DMSO}-d_{6}\right): \delta=54.1\left(\mathrm{~S}-\mathrm{CH}_{2}\right), 138.1(\mathrm{CO}-\mathrm{CH}), 144.2(\mathrm{CH}-\mathrm{S}), 171.4(\mathrm{COOH}), 184.2$ $(\mathrm{C}=\mathrm{O}), 128.4,130.6,132.4,141.5$ (aromatic carbons); IR $(\mathrm{KBr}): v=3218(\mathrm{OH}), 1714(\mathrm{C}=\mathrm{O})$, $1664($ Ar- $\mathrm{C}=\mathrm{O}), 1574(\mathrm{C}=\mathrm{C})$.

E-Benzoylethenesulfonylacetic acid (3a). Typical procedure. The compound 2 (10 mmol) was subjected to oxidation with $30 \%$ hydrogen peroxide $(2 \mathrm{~mL})$ in glacial acetic acid $(6.5 \mathrm{~mL})$. The contents were stirred at $0{ }^{\circ} \mathrm{C}$ for $4 \mathrm{~h}$. and kept aside for $36 \mathrm{~h}$. The reaction mixture was poured onto crushed ice. The solid separated was filtered and recrystallized from water to get pure 3a. Yield 2.237 g (88\%); white solid; m. p. 132-134 ${ }^{\circ} \mathrm{C}$; ${ }^{1} \mathrm{H}$ NMR $\left(300 \mathrm{MHz}, \mathrm{DMSO}-d_{6}\right): \delta=4.38$ (s, $\left.2 \mathrm{H}, \mathrm{SO}_{2}-\mathrm{CH}_{2}\right), 7.66\left(\mathrm{~d}, J=14.2 \mathrm{~Hz}, 1 \mathrm{H}, \mathrm{H}_{\mathrm{B}}\right.$ ) $, 7.96\left(\mathrm{~d}, J=14.2 \mathrm{~Hz}, 1 \mathrm{H}, \mathrm{H}_{\mathrm{A}}\right), 7.56-7.88(\mathrm{~m}, 5 \mathrm{H}$, $\mathrm{Ar}-\mathrm{H}), 9.68$ (bs, $1 \mathrm{H}, \mathrm{OH}) ;{ }^{13} \mathrm{C} \mathrm{NMR}\left(300 \mathrm{MHz}, \mathrm{DMSO}-d_{6}\right): \delta=56.8\left(\mathrm{SO}_{2}-\mathrm{CH}_{2}\right), 138.7$ (CO$\mathrm{CH}), 141.8\left(\mathrm{CH}-\mathrm{SO}_{2}\right), 172.8(\mathrm{COOH}), 182.4(\mathrm{C}=\mathrm{O}), 128.4,129.4,132.6,134.4$ (aromatic carbons); IR $(\mathrm{KBr}): v=3221(\mathrm{OH}), 1727(\mathrm{C}=\mathrm{O}), 1662(\mathrm{Ar}-\mathrm{C}=\mathrm{O}), 1584(\mathrm{C}=\mathrm{C}), 1326,1130$ $\left(\mathrm{SO}_{2}\right)$.

$\boldsymbol{E}$-(p-Methylbenzoyl)ethenesulfonylacetic acid (3b). Yield $2.280 \mathrm{~g}$ (85\%); white solid; m. p. 125-127 ${ }^{\circ} \mathrm{C}$; ${ }^{1} \mathrm{H}$ NMR (300 MHz, DMSO-d $): \delta=2.24$ (s, $\left.2 \mathrm{H},-\mathrm{CH}_{3}\right), 4.40\left(\mathrm{~s}, 2 \mathrm{H}, \mathrm{SO}_{2}-\mathrm{CH}_{2}\right)$, $7.63\left(\mathrm{~d}, J=14.4 \mathrm{~Hz}, 1 \mathrm{H}, \mathrm{H}_{\mathrm{B}}\right), 7.92\left(\mathrm{~d}, J=14.4 \mathrm{~Hz}, 1 \mathrm{H}, \mathrm{H}_{\mathrm{A}}\right), 7.42-7.80$ (m, 4H, Ar-H), 9.92 (bs, $1 \mathrm{H}, \mathrm{OH}) ;{ }^{13} \mathrm{C}$ NMR $\left(300 \mathrm{MHz}, \mathrm{DMSO}-d_{6}\right): \delta=24.2\left(-\mathrm{CH}_{3}\right), 57.2\left(\mathrm{SO}_{2}-\mathrm{CH}_{2}\right), 137.6(\mathrm{CO}-\mathrm{CH})$, $142.3\left(\mathrm{CH}-\mathrm{SO}_{2}\right), 172.3(\mathrm{COOH}), 181.3(\mathrm{C}=\mathrm{O}), 128.2,129.2,131.9,135.4$ (aromatic carbons); IR $(\mathrm{KBr}): v=3224(\mathrm{OH}), 1714(\mathrm{C}=\mathrm{O}), 1658(\mathrm{Ar}-\mathrm{C}=\mathrm{O}), 1568(\mathrm{C}=\mathrm{C}), 1314,1132\left(\mathrm{SO}_{2}\right)$. 
$\boldsymbol{E}$-(p-Chlorobenzoyl)ethenesulfonylacetic acid (3c). Yield 2.512 g (87\%); white solid; m. p. 151-153 ${ }^{\circ} \mathrm{C}$; ${ }^{1} \mathrm{H}$ NMR (300 MHz, DMSO-d $): \delta=4.42$ (s, 2H, $\mathrm{SO}_{2}-\mathrm{CH}_{2}$ ), 7.69 (d, $J=14.6 \mathrm{~Hz}$, $\left.1 \mathrm{H}, \mathrm{H}_{\mathrm{B}}\right), 7.98\left(\mathrm{~d}, J=14.3 \mathrm{~Hz}, 1 \mathrm{H}, \mathrm{H}_{\mathrm{A}}\right), 7.52-7.87(\mathrm{~m}, 4 \mathrm{H}, \mathrm{Ar}-\mathrm{H}), 9.96(\mathrm{bs}, 1 \mathrm{H}, \mathrm{OH}) ;{ }^{13} \mathrm{C} \mathrm{NMR}$ $\left(300 \mathrm{MHz}, \mathrm{DMSO}-d_{6}\right): \delta=56.5\left(\mathrm{SO}_{2}-\mathrm{CH}_{2}\right), 138.1(\mathrm{CO}-\mathrm{CH}), 142.6\left(\mathrm{CH}-\mathrm{SO}_{2}\right), 173.2(\mathrm{COOH})$, $179.6(\mathrm{C}=\mathrm{O}), 128.1,129.6,132.3,134.2$ (aromatic carbons); IR $(\mathrm{KBr}): v=3218(\mathrm{OH}), 1724$ $(\mathrm{C}=\mathrm{O}), 1666(\mathrm{Ar}-\mathrm{C}=\mathrm{O}), 1564(\mathrm{C}=\mathrm{C}), 1336,1138\left(\mathrm{SO}_{2}\right)$.

E-Benzoylethenesulfonylacetic acid methyl ester (4a). Typical procedure. To a solution of compound 3 (10 mmol) in methanol $(20 \mathrm{~mL})$, sulfuric acid $(4 \mathrm{~mL})$ was added and refluxed for 6$8 \mathrm{~h}$. The contents were cooled and poured onto crushed ice. The solid separated was filtered and recrystallized from methanol to get pure 4a. Yield $2.280 \mathrm{~g}(85 \%)$; white crystals; m. p. $94-96{ }^{\circ} \mathrm{C}$; ${ }^{1} \mathrm{H}$ NMR (300 MHz, DMSO-d $\left.d_{6}\right): \delta=3.78\left(\mathrm{~s}, 3 \mathrm{H},-\mathrm{OCH}_{3}\right), 4.36\left(\mathrm{~s}, 2 \mathrm{H}, \mathrm{SO}_{2}-\mathrm{CH}_{2}\right), 7.65(\mathrm{~d}, J=$ $\left.13.9 \mathrm{~Hz}, 1 \mathrm{H}, \mathrm{H}_{\mathrm{B}}\right), 7.91\left(\mathrm{~d}, J=13.7 \mathrm{~Hz}, 1 \mathrm{H}, \mathrm{H}_{\mathrm{A}}\right), 7.36-7.52(\mathrm{~m}, 5 \mathrm{H}, \mathrm{Ar}-\mathrm{H}) ;{ }^{13} \mathrm{C} \mathrm{NMR}(300 \mathrm{MHz}$, DMSO-d $\left.)_{6}\right): \delta=53.1\left(\mathrm{OCH}_{3}\right), 59.6\left(\mathrm{SO}_{2}-\mathrm{CH}_{2}\right), 138.4(\mathrm{CO}-\mathrm{CH}), 145.6\left(\mathrm{CH}-\mathrm{SO}_{2}\right), 168.1$ $\left(\mathrm{CO}_{2} \mathrm{CH}_{3}\right), 182.4(\mathrm{C}=\mathrm{O}), 130.5,132.3,137.5,139.4$ (aromatic carbons); IR (KBr): $v=1746$ $\left(\mathrm{CO}_{2} \mathrm{Me}\right), 1668(\mathrm{C}=\mathrm{O}), 1579(\mathrm{C}=\mathrm{C}), 1316,1142\left(\mathrm{SO}_{2}\right)$; Anal. Calcd. for $\mathrm{C}_{12} \mathrm{H}_{12} \mathrm{O}_{5} \mathrm{~S}$ (268.29): C, 53.72 ; H, 4.51. Found: C, 53.78; H, 4.49.

$\boldsymbol{E}$-(p-Methylbenzoyl)ethenesulfonylacetic acid methyl ester (4b). Yield $2.512 \mathrm{~g}(89 \%)$; white crystals; m. p. 101-103 ${ }^{\circ} \mathrm{C} ;{ }^{1} \mathrm{H}$ NMR (300 MHz, DMSO- $\left.d_{6}\right): \delta=2.28\left(\mathrm{~s}, 3 \mathrm{H}, \mathrm{CH}_{3}\right), 3.72(\mathrm{~s}, 3 \mathrm{H}$, $\left.\mathrm{OCH}_{3}\right), 4.32\left(\mathrm{~s}, 2 \mathrm{H}, \mathrm{SO}_{2}-\mathrm{CH}_{2}\right), 7.62\left(\mathrm{~d}, J=13.7 \mathrm{~Hz}, 1 \mathrm{H}, \mathrm{H}_{\mathrm{B}}\right), 7.88\left(\mathrm{~d}, J=13.7 \mathrm{~Hz}, 1 \mathrm{H}, \mathrm{H}_{\mathrm{A}}\right)$, 7.32-7.54 (m, 4H, Ar-H); ${ }^{13} \mathrm{C}$ NMR (300 MHz, DMSO-d $): \delta=23.1\left(\mathrm{CH}_{3}\right), 53.4\left(\mathrm{OCH}_{3}\right), 58.1$ $\left(\mathrm{SO}_{2}-\mathrm{CH}_{2}\right), 138.1(\mathrm{CO}-\mathrm{CH}), 146.1\left(\mathrm{CH}-\mathrm{SO}_{2}\right), 167.4\left(\mathrm{CO}_{2} \mathrm{CH}_{3}\right), 181.3(\mathrm{C}=\mathrm{O}), 129.4,131.6$, 136.3, 138.4 (aromatic carbons); IR $(\mathrm{KBr}): v=1749\left(\mathrm{CO}_{2} \mathrm{Me}\right), 1662(\mathrm{C}=\mathrm{O}), 1574(\mathrm{C}=\mathrm{C}), 1341$, $1128\left(\mathrm{SO}_{2}\right)$; Anal. Calcd. for $\mathrm{C}_{13} \mathrm{H}_{14} \mathrm{O}_{5} \mathrm{~S}$ (282.31): C, 55.31; H, 5.00. Found: C, 55.34; H, 5.02.

$\boldsymbol{E}$-(p-Chlorobenzoyl)ethenesulfonylacetic acid methyl ester (4c). Yield $2.634 \mathrm{~g}$ (87\%); white crystals; m. p. $124-126{ }^{\circ} \mathrm{C} ;{ }^{1} \mathrm{H}$ NMR (300 MHz, DMSO- $\left.d_{6}\right): \delta=3.75$ (s, 3H, $\left.\mathrm{OCH}_{3}\right), 4.38(\mathrm{~s}, 2 \mathrm{H}$, $\left.\mathrm{SO}_{2}-\mathrm{CH}_{2}\right), 7.69\left(\mathrm{~d}, J=14.2 \mathrm{~Hz}, 1 \mathrm{H}, \mathrm{H}_{\mathrm{B}}\right), 7.94\left(\mathrm{~d}, J=14.2 \mathrm{~Hz}, 1 \mathrm{H}, \mathrm{H}_{\mathrm{A}}\right), 7.48-7.72(\mathrm{~m}, 4 \mathrm{H}, \mathrm{Ar}-$ $\mathrm{H}) ;{ }^{13} \mathrm{C}$ NMR $\left(300 \mathrm{MHz}, \mathrm{DMSO}-d_{6}\right): \delta=53.8\left(\mathrm{OCH}_{3}\right), 58.9\left(\mathrm{SO}_{2}-\mathrm{CH}_{2}\right), 138.9(\mathrm{CO}-\mathrm{CH}), 147.3$ $\left(\mathrm{CH}-\mathrm{SO}_{2}\right), 168.6\left(\mathrm{CO}_{2} \mathrm{CH}_{3}\right), 181.6(\mathrm{C}=\mathrm{O}), 128.9,131.4,135.8,137.4$ (aromatic carbons); IR $(\mathrm{KBr}): v=1752\left(\mathrm{CO}_{2} \mathrm{Me}\right), 1669(\mathrm{C}=\mathrm{O}), 1568(\mathrm{C}=\mathrm{C}), 1325,1149\left(\mathrm{SO}_{2}\right)$; Anal. Calcd. for $\mathrm{C}_{12} \mathrm{H}_{11} \mathrm{ClO}_{5} \mathrm{~S}$ (302.73): C, 47.61; H, 3.66. Found: C, 47.55; H, 3.69.

\section{2-(Aroylethenesulfonylmethyl)-4,5-dihydrooxazole (5) / 2-(Aroylethenesulfonyl-methyl)-} 4,5-dihydrothiazole (6). Typical procedure. To a flask charged with anhydrous samarium chloride $(0.1 \mathrm{mmol})$, dry toluene $(10 \mathrm{~mL})$ and $2 \mathrm{mmols}$ of aminoethanol / aminoethanethiol were added followed by $2.2 \mathrm{mmol}$ of $n$-butyllithium at $0{ }^{\circ} \mathrm{C}$. The reaction mixture was stirred at $0{ }^{\circ} \mathrm{C}$ for $30 \mathrm{~min}$. Then the contents were refluxed to $120^{\circ} \mathrm{C}$ and $1 \mathrm{mmol}$ of aroylethenesulfonylacetic acid methyl ester (4) was added and continued the refluxion for an additional period of 12-14 h. The suspension was cooled to room temperature and filtered. The filtrate was extracted with chloroform, washed with water followed by brine solution. The solvent was removed in vacuo. 
The product was purified by column chromatography [silica gel (60-120 mesh), EtOAc- hexane $1: 3]$.

2-(Benzoylethenesulfonylmethyl)-4,5-dihydrooxazole (5a). Yield $0.213 \mathrm{~g} \mathrm{(77 \% );} \mathrm{white} \mathrm{solid;}$ m. p. $117-119{ }^{\circ} \mathrm{C} ;{ }^{1} \mathrm{H}$ NMR $\left(300 \mathrm{MHz}, \mathrm{DMSO}-d_{6}\right): \delta=3.78(\mathrm{t}, J=5.9 \mathrm{~Hz}, 2 \mathrm{H}, \mathrm{H}-4), 4.29$ (s, 2H, $\left.\mathrm{SO}_{2}-\mathrm{CH}_{2}\right), 4.88(\mathrm{t}, J=5.9 \mathrm{~Hz}, 2 \mathrm{H}, \mathrm{H}-5), 7.62\left(\mathrm{~d}, J=14.4 \mathrm{~Hz}, 1 \mathrm{H}, \mathrm{H}_{\mathrm{B}}\right.$ ) $), 7.96(\mathrm{~d}, J=14.4 \mathrm{~Hz}$, $\left.1 \mathrm{H}, \mathrm{H}_{\mathrm{A}},\right), 7.46-7.56(\mathrm{~m}, 5 \mathrm{H}, \mathrm{Ar}-\mathrm{H}) ;{ }^{13} \mathrm{C} \mathrm{NMR}\left(300 \mathrm{MHz}, \mathrm{DMSO}-d_{6}\right): \delta=52.4(\mathrm{C}-4), 55.2\left(\mathrm{SO}_{2^{-}}\right.$ $\left.\mathrm{CH}_{2}\right), 57.8(\mathrm{C}-5), 137.1(\mathrm{CO}-\mathrm{CH}), 144.4\left(\mathrm{CH}-\mathrm{SO}_{2}\right), 158.9(\mathrm{C}-2), 182.4(\mathrm{C}=\mathrm{O}), 127.8,129.8$, 131.6, 132.3 (aromatic carbons); IR $(\mathrm{KBr}): v=1662(\mathrm{C}=\mathrm{O}), 1578(\mathrm{C}=\mathrm{N}), 1563(\mathrm{C}=\mathrm{C}), 1325$, $1149\left(\mathrm{SO}_{2}\right)$; Anal. Calcd. for $\mathrm{C}_{13} \mathrm{H}_{11} \mathrm{NO}_{4} \mathrm{~S}(277.30)$ : C, 56.31; H, 4.00; N, 5.05. Found: C, 56.37; H, 3.97; N, 5.09.

2-(p-Methylbenzoylethenesulfonylmethyl)-4,5-dihydrooxazole (5b). Yield $0.239 \mathrm{~g}$ (82\%); white solid; m. p. $132-134{ }^{\circ} \mathrm{C} ;{ }^{1} \mathrm{H}$ NMR (300 MHz, DMSO- $\left.d_{6}\right): \delta=2.24\left(\mathrm{~s}, 3 \mathrm{H}, \mathrm{CH}_{3}\right), 3.82(\mathrm{t}, J$ $=5.7 \mathrm{~Hz}, 2 \mathrm{H}, \mathrm{H}-4), 4.32\left(\mathrm{~s}, 2 \mathrm{H}, \mathrm{SO}_{2}-\mathrm{CH}_{2}\right), 4.79(\mathrm{t}, J=5.7 \mathrm{~Hz}, 2 \mathrm{H}, \mathrm{H}-5), 7.68$ (d, J=14.2 Hz, $\left.1 \mathrm{H}, \mathrm{H}_{\mathrm{B}}\right), 7.85\left(\mathrm{~d}, J=14.2 \mathrm{~Hz}, 1 \mathrm{H}, \mathrm{H}_{\mathrm{A}}\right), 7.34-7.53$ (m, 4H,Ar-H); ${ }^{13} \mathrm{C}$ NMR $(300 \mathrm{MHz}, \mathrm{DMSO}-$ $\left.d_{6}\right): \delta=21.8\left(\mathrm{CH}_{3}\right), 52.8(\mathrm{C}-4), 55.8\left(\mathrm{SO}_{2}-\mathrm{CH}_{2}\right), 56.9(\mathrm{C}-5), 137.4(\mathrm{CO}-\mathrm{CH}), 143.8\left(\mathrm{CH}-\mathrm{SO}_{2}\right)$, $161.4(\mathrm{C}-2), 181.7(\mathrm{C}=\mathrm{O}), 127.1,128.4,129.2,132.3$ (aromatic carbons); IR (KBr): $v=1668$ $(\mathrm{C}=\mathrm{O}), 1574(\mathrm{C}=\mathrm{N}), 1561(\mathrm{C}=\mathrm{C}), 1331,1138\left(\mathrm{SO}_{2}\right)$; Anal. Calcd. for $\mathrm{C}_{14} \mathrm{H}_{13} \mathrm{NO}_{4} \mathrm{~S}$ (291.32): $\mathrm{C}$, 57.72; H, 4.50; N, 4.81. Found: C, 57.79; H, 4.55; N, 4.86 .

2-(p-Chlorobenzoylethenesulfonylmethyl)-4,5-dihydrooxazole (5c). Yield 0.206 g (66\%); white solid; m. p. 141-142 ${ }^{\circ} \mathrm{C} ;{ }^{1} \mathrm{H}$ NMR (300 MHz, DMSO- $\left.d_{6}\right): \delta=3.72$ (t, $\left.J=5.4 \mathrm{~Hz}, \mathrm{H}-4\right)$, $4.35\left(\mathrm{~s}, 2 \mathrm{H}, \mathrm{SO}_{2}-\mathrm{CH}_{2}\right), 4.92(\mathrm{t}, J=5.4 \mathrm{~Hz}, 2 \mathrm{H}, \mathrm{H}-5), 7.69$ (d, $\left.J=14.4 \mathrm{~Hz}, 1 \mathrm{H}, \mathrm{H}_{\mathrm{B}}\right), 7.91(\mathrm{~d}, J=$ $\left.14.4 \mathrm{~Hz}, 1 \mathrm{H}, \mathrm{H}_{\mathrm{A}}\right), 7.48-7.64(\mathrm{~m}, 4 \mathrm{H}, \mathrm{Ar}-\mathrm{H}) ;{ }^{13} \mathrm{C}$ NMR $\left(300 \mathrm{MHz}, \mathrm{DMSO}-d_{6}\right): \delta=53.1(\mathrm{C}-4)$, $56.2\left(\mathrm{SO}_{2}-\mathrm{CH}_{2}\right), 58.1(\mathrm{C}-5), 138.2(\mathrm{CO}-\mathrm{CH}), 142.4\left(\mathrm{CH}-\mathrm{SO}_{2}\right), 160.6(\mathrm{C}-2), 183.6(\mathrm{C}=\mathrm{O}), 128.4$, 129.2, 129.8, 133.6 (aromatic carbons); IR (KBr): $v=1671(\mathrm{C}=\mathrm{O}), 1568(\mathrm{C}=\mathrm{N}), 1562(\mathrm{C}=\mathrm{C})$, 1328, $1142\left(\mathrm{SO}_{2}\right)$; Anal. Calcd. for $\mathrm{C}_{13} \mathrm{H}_{10} \mathrm{ClNO}_{4} \mathrm{~S}$ (311.74): C, 50.09; H, 3.23; N, 4.49. Found: C, 50.02; H, 3.26; N, 4.42 .

2-(Benzoylethenesulfonylmethyl)-4,5-dihydrothiazole (6a). Yield $0.201 \mathrm{~g}$ (68\%); white solid; m. p. $108-110{ }^{\circ} \mathrm{C} ;{ }^{1} \mathrm{H}$ NMR (300 MHz, DMSO- $\left.d_{6}\right): \delta=3.38(\mathrm{t}, J=8.3 \mathrm{~Hz}, 2 \mathrm{H}, \mathrm{H}-5), 3.91$ (t, $J=$ $8.3 \mathrm{~Hz}, 2 \mathrm{H}, \mathrm{H}-4), 4.23$ (s, 2H, SO $\mathrm{SO}_{2} \mathrm{CH}_{2}$ ), 7.61 (d, $J=14.3 \mathrm{~Hz}, 1 \mathrm{H}, \mathrm{H}_{\mathrm{B}}$ ), 7.89 (d, $J=14.3 \mathrm{~Hz}$, $\left.1 \mathrm{H}, \mathrm{H}_{\mathrm{A}}\right), 7.42-7.74(\mathrm{~m}, 5 \mathrm{H}, \mathrm{Ar}-\mathrm{H}) ;{ }^{13} \mathrm{C} \mathrm{NMR}\left(300 \mathrm{MHz}, \mathrm{DMSO}-d_{6}\right): \delta=37.8(\mathrm{C}-5), 54.2(\mathrm{C}-4)$, $56.8\left(\mathrm{SO}_{2}-\mathrm{CH}_{2}\right), 136.8(\mathrm{CO}-\mathrm{CH}), 143.9\left(\mathrm{CH}-\mathrm{SO}_{2}\right), 162.3(\mathrm{C}-2), 181.7(\mathrm{C}=\mathrm{O}), 127.3,128.2$, 129.1, 131.8 (aromatic carbons); IR $(\mathrm{KBr}): v=1677(\mathrm{C}=\mathrm{O}), 1573(\mathrm{C}=\mathrm{N}), 1564(\mathrm{C}=\mathrm{C}), 1331$, $1142\left(\mathrm{SO}_{2}\right)$; Anal. Calcd. for $\mathrm{C}_{13} \mathrm{H}_{13} \mathrm{NO}_{3} \mathrm{~S}_{2}$ (295.38): C, 52.86; H, 4.44; N, 4.74. Found: $\mathrm{C}, 52.81$; $\mathrm{H}, 4.48 ; \mathrm{N}, 4.70$.

2-(p-Methylbenzoylethenesulfonylmethyl)-4,5-dihydrothiazole (6b). Yield $0.195 \mathrm{~g}$ (63\%); white solid; m. p. $120-122{ }^{\circ} \mathrm{C} ;{ }^{1} \mathrm{H}$ NMR (300 MHz, DMSO- $\left.d_{6}\right): \delta=2.34$ (s, $\left.3 \mathrm{H}, \mathrm{CH}_{3}\right), 3.31$ (t, $J$ $=8.3 \mathrm{~Hz}, 2 \mathrm{H}, \mathrm{H}-5), 3.88(\mathrm{t}, J=8.3 \mathrm{~Hz}, 2 \mathrm{H}, \mathrm{H}-4), 4.21\left(\mathrm{~s}, 2 \mathrm{H}, \mathrm{SO}_{2}-\mathrm{CH}_{2}\right), 7.64(\mathrm{~d}, J=14.1 \mathrm{~Hz}$, $\left.1 \mathrm{H}, \mathrm{H}_{\mathrm{B}}\right), 7.88\left(\mathrm{~d}, J=14.1 \mathrm{~Hz}, 1 \mathrm{H}, \mathrm{H}_{\mathrm{A}}\right), 7.36-7.72(\mathrm{~m}, 4 \mathrm{H}, \mathrm{Ar}-\mathrm{H}) ;{ }^{13} \mathrm{C}$ NMR $(300 \mathrm{MHz}, \mathrm{DMSO}-$ $\left.d_{6}\right): \delta=22.3\left(\mathrm{CH}_{3}\right), 37.3(\mathrm{C}-5), 55.6(\mathrm{C}-4), 56.6\left(\mathrm{SO}_{2}-\mathrm{CH}_{2}\right), 136.1(\mathrm{CO}-\mathrm{CH}), 143.2\left(\mathrm{CH}-\mathrm{SO}_{2}\right)$, $159.2(\mathrm{C}-2), 180.6(\mathrm{C}=\mathrm{O}), 126.8,128.4,129.6,130.2$ (aromatic carbons); IR (KBr): $v=1681$ 
$(\mathrm{C}=\mathrm{O}), 1574(\mathrm{C}=\mathrm{N}), 1559(\mathrm{C}=\mathrm{C}), 1328,1144\left(\mathrm{SO}_{2}\right)$; Anal. Calcd. for $\mathrm{C}_{14} \mathrm{H}_{15} \mathrm{NO}_{3} \mathrm{~S}_{2}(309.40)$ : $\mathrm{C}$, $54.35 ; \mathrm{H}, 4.89$; N, 4.53. Found: C, 54.39; H, 4.92; N, 4.61.

2-(p-Chlorobenzoylethenesulfonylmethyl)-4,5-dihydrothiazole (6c). Yield $0.214 \mathrm{~g}$ (65\%); white solid; m. p. $133-135{ }^{\circ} \mathrm{C} ;{ }^{1} \mathrm{H}$ NMR (300 MHz, DMSO- $\left.d_{6}\right): \delta=3.37$ (t, $\left.J=7.5 \mathrm{~Hz}, 2 \mathrm{H}, \mathrm{H}-5\right)$, $3.92(\mathrm{t}, J=7.5 \mathrm{~Hz}, 2 \mathrm{H}, \mathrm{H}-4), 4.31\left(\mathrm{~s}, 2 \mathrm{H}, \mathrm{SO}_{2}-\mathrm{CH}_{2}\right), 7.62\left(\mathrm{~d}, J=14.1 \mathrm{~Hz}, 1 \mathrm{H}, \mathrm{H}_{\mathrm{B}}\right), 7.81$ (d, $J=$ $\left.14.1 \mathrm{~Hz}, 1 \mathrm{H}, \mathrm{H}_{\mathrm{A}}\right), 7.46-7.75(\mathrm{~m}, 4 \mathrm{H}, \mathrm{Ar}-\mathrm{H}) ;{ }^{13} \mathrm{C}$ NMR $\left(300 \mathrm{MHz}, \mathrm{DMSO}-d_{6}\right): \delta=36.9(\mathrm{C}-5)$, $55.4(\mathrm{C}-4), 57.9\left(\mathrm{SO}_{2}-\mathrm{CH}_{2}\right), 136.8(\mathrm{CO}-\mathrm{CH}), 142.8\left(\mathrm{CH}-\mathrm{SO}_{2}\right), 159.4(\mathrm{C}-2), 181.4(\mathrm{C}=\mathrm{O}), 127.6$, 128.9, 131.4, 137.2 (aromatic carbons); IR $(\mathrm{KBr}): v=1676(\mathrm{C}=\mathrm{O}), 1568(\mathrm{C}=\mathrm{N}), 1561(\mathrm{C}=\mathrm{C})$, 1330, $1143\left(\mathrm{SO}_{2}\right)$; Anal. Calcd. for $\mathrm{C}_{13} \mathrm{H}_{12} \mathrm{ClNO}_{3} \mathrm{~S}_{2}$ (329.82): C, 47.34; H, 3.67; N, 4.25 . Found: C, 47.39; H, 3.64; N, 4.31 .

2-(4'-Aroyl-1'H-pyrrol-3'-sulfonylmethyl)-4,5-dihydrooxazole (7a) / 2-(4'-Aroyl-1' H-pyrrol3'-sulfonylmethyl)-4,5-dihydrothiazole (8a). Typical procedure. A mixture of $1 \mathrm{mmol}$ of TosMIC and $1 \mathrm{mmol}$ of 2-(aroylethenesulfonylmethyl)-4,5-dihydrooxazole / 2(aroylethenesulfonylmethyl)-4,5-dihydrothiazole (5/6) in $\mathrm{Et}_{2} \mathrm{O} / \mathrm{DMSO}$ (2:1) was added dropwise to a stirred mixture of $\mathrm{NaH}(50 \mathrm{mg})$ in dry $\mathrm{Et}_{2} \mathrm{O}(10 \mathrm{~mL})$ at room temperature and stirring was continued for 12-14 h. Then the reaction mixture was diluted with water and extracted with ether. The ethereal layer was dried (over anhydrous $\mathrm{Na}_{2} \mathrm{SO}_{4}$ ) and the solvent was removed under reduced pressure. The resultant solid was purified by passing through a column chromatography [silica gel (60-120 mesh), EtOAc- hexane 1.5:3] as eluent.

2-(4'-(Benzoyl-1'H-pyrrol-3'-sulfonylmethyl)-4,5-dihydrooxazole (7a). Yield $0.197 \mathrm{~g}$ (62\%); pale yellow solid; m. p. 189-191 ${ }^{\circ} \mathrm{C}$; ${ }^{1} \mathrm{H}$ NMR (300 MHz, DMSO- $\left.d_{6}\right): \delta=3.73(\mathrm{t}, J=5.3 \mathrm{~Hz}, 2 \mathrm{H}$, H-4), 4.21 (s, 2H, SO $-\mathrm{CH}_{2}$ ), 4.94 (t, J=5.3 Hz, 2H, H-5), 6.48 (s, 1H, H-2'), 6.96 (s, 1H, H-5'), 7.35-7.58 (m, 5H, Ar-H), 9.21 (bs, $1 \mathrm{H}, \mathrm{NH}) ;{ }^{13} \mathrm{C}$ NMR (300 MHz, DMSO- $\left.d_{6}\right): \delta=52.4(\mathrm{C}-4)$, $55.9\left(\mathrm{SO}_{2}-\mathrm{CH}_{2}\right), 58.2(\mathrm{C}-5), 102.4\left(\mathrm{C}-4^{\prime}\right), 105.2\left(\mathrm{C}-3^{\prime}\right), 116.8\left(\mathrm{C}-2^{\prime}\right), 119.6\left(\mathrm{C}-5^{\prime}\right), 159.7(\mathrm{C}-2)$, $180.2(\mathrm{C}=\mathrm{O}), 127.9,129.6,131.4,132.6$ (aromatic carbons); IR $(\mathrm{KBr}): v=3208(\mathrm{NH}), 1678$ $(\mathrm{C}=\mathrm{O}), 1573(\mathrm{C}=\mathrm{N}), 1330,1148\left(\mathrm{SO}_{2}\right)$; Anal. Calcd. for $\mathrm{C}_{15} \mathrm{H}_{14} \mathrm{~N}_{2} \mathrm{O}_{4} \mathrm{~S}$ (318.35): C, 56.59; $\mathrm{H}$, 4.43 ; N, 8.80. Found: C, 56.54; H, 4.44; N, 8.69.

2-(4'-(p-Methylbenzoyl-1' $\boldsymbol{H}$-pyrrol-3'-sulfonylmethyl)-4,5-dihydrooxazole (7b). Yield 0.236 g (71\%); pale yellow solid; m. p. $176-178{ }^{\circ} \mathrm{C} ;{ }^{1} \mathrm{H}$ NMR $\left(300 \mathrm{MHz}, \mathrm{DMSO}-d_{6}\right): \delta=2.24$ (s, $3 \mathrm{H}$, $\left.\mathrm{CH}_{3}\right), 3.84$ (t, $\left.J=5.8 \mathrm{~Hz}, 2 \mathrm{H}, \mathrm{H}-4\right), 4.27\left(\mathrm{~s}, 2 \mathrm{H}, \mathrm{SO}_{2}-\mathrm{CH}_{2}\right), 4.87$ (t, $\left.J=5.8 \mathrm{~Hz}, 2 \mathrm{H}, \mathrm{H}-5\right), 6.45$ (s, $\left.1 \mathrm{H}, \mathrm{H}-2^{\prime}\right), 6.91$ (s, $\left.1 \mathrm{H}, \mathrm{H}-5^{\prime}\right), 7.27-7.52$ (m, 4H, Ar-H), 9.26 (bs, $\left.1 \mathrm{H}, \mathrm{NH}\right) ;{ }^{13} \mathrm{C} \mathrm{NMR}(300 \mathrm{MHz}$, DMSO- $\left.d_{6}\right): \delta=23.5\left(\mathrm{CH}_{3}\right), 52.5(\mathrm{C}-4), 54.8\left(\mathrm{SO}_{2}-\mathrm{CH}_{2}\right), 57.9(\mathrm{C}-5), 101.9\left(\mathrm{C}-4^{\prime}\right), 105.8\left(\mathrm{C}-3^{\prime}\right)$, $115.9\left(\mathrm{C}-2^{\prime}\right), 119.1\left(\mathrm{C}-5^{\prime}\right), 158.6(\mathrm{C}-2), 181.8(\mathrm{C}=\mathrm{O}), 127.2,127.9,129.1,130.7$ (aromatic carbons); IR $(\mathrm{KBr}): v=3210(\mathrm{NH}), 1672(\mathrm{C}=\mathrm{O}), 1577(\mathrm{C}=\mathrm{N}), 1334,1142\left(\mathrm{SO}_{2}\right)$; Anal. Calcd. for $\mathrm{C}_{16} \mathrm{H}_{16} \mathrm{~N}_{2} \mathrm{O}_{4} \mathrm{~S}$ (332.37): C, 57.82; H, 4.85; N, 8.43. Found: C, 57.87; H, 4.82; N, 8.38.

2-(4'-(p-Chlorobenzoyl-1'H-pyrrol-3'-sulfonylmethyl)-4,5-dihydrooxazole $\quad$ (7c). Yield 0.215 g (61\%); pale yellow solid; m. p. $212-214{ }^{\circ} \mathrm{C} ;{ }^{1} \mathrm{H}$ NMR $\left(300 \mathrm{MHz}, \mathrm{DMSO}-d_{6}\right): \delta=3.89(\mathrm{t}$, $J=5.6 \mathrm{~Hz}, 2 \mathrm{H}, \mathrm{H}-4), 4.21\left(\mathrm{~s}, 2 \mathrm{H}, \mathrm{SO}_{2}-\mathrm{CH}_{2}\right), 4.96$ (t, $\left.J=5.6 \mathrm{~Hz}, 2 \mathrm{H}, \mathrm{H}-5\right), 6.39$ (s, 1H, H-2'), $6.86\left(\mathrm{~s}, 1 \mathrm{H}, \mathrm{H}-5^{\prime}\right), 7.38-7.62$ (m, 4H, Ar-H), 9.28 (bs, 1H, NH); ${ }^{13} \mathrm{C}$ NMR (300 MHz, DMSO- 
$\left.d_{6}\right): \delta=52.8(\mathrm{C}-4), 54.4\left(\mathrm{SO}_{2}-\mathrm{CH}_{2}\right), 57.4(\mathrm{C}-5), 102.1\left(\mathrm{C}-4^{\prime}\right), 106.2\left(\mathrm{C}-3^{\prime}\right), 115.1\left(\mathrm{C}-2^{\prime}\right), 120.1$ $\left(\mathrm{C}-5^{\prime}\right), 160.1(\mathrm{C}-2), 181.7(\mathrm{C}=\mathrm{O}), 128.2,129.6,132.1,135.7$ (aromatic carbons); IR $(\mathrm{KBr}): v=$ $3218(\mathrm{NH}), 1673(\mathrm{C}=\mathrm{O}), 1571(\mathrm{C}=\mathrm{N}), 1339,1148\left(\mathrm{SO}_{2}\right)$; Anal. Calcd. for $\mathrm{C}_{15} \mathrm{H}_{13} \mathrm{ClN}_{2} \mathrm{O}_{4} \mathrm{~S}$ (352.79): C, 51.07; H, 3.71; N, 7.94. Found: C, 51.14; H, 3.74; N, 8.02.

2-(4'-Benzoyl-1' $\boldsymbol{H}$-pyrrol-3'-sulfonylmethyl)-4,5-dihydrothiazole (8a). Yield $0.214 \mathrm{~g}(64 \%)$; pale yellow solid; m. p. $176-178{ }^{\circ} \mathrm{C} ;{ }^{1} \mathrm{H}$ NMR $\left(300 \mathrm{MHz}, \mathrm{DMSO}-d_{6}\right): \delta=3.36(\mathrm{t}, J=7.3 \mathrm{~Hz}, 2 \mathrm{H}$, $\mathrm{H}-5), 3.95$ (t, $J=7.3 \mathrm{~Hz}, 2 \mathrm{H}, \mathrm{H}-4), 4.17$ (s, $\left.2 \mathrm{H}, \mathrm{SO}_{2}-\mathrm{CH}_{2}\right), 6.56$ (s, $\left.1 \mathrm{H}, \mathrm{H}-2^{\prime}\right), 6.78$ (s, 1H, H-5'), 7.38-7.71 (m, $5 \mathrm{H}, \mathrm{Ar}-\mathrm{H}), 9.13(\mathrm{bs}, 1 \mathrm{H}, \mathrm{NH}) ;{ }^{13} \mathrm{C}$ NMR (300 MHz, DMSO- $\left.d_{6}\right): \delta=37.4(\mathrm{C}-5)$, 53.2 (C-4), $56.6\left(\mathrm{SO}_{2}-\mathrm{CH}_{2}\right), 103.6\left(\mathrm{C}-4^{\prime}\right), 104.8\left(\mathrm{C}-3^{\prime}\right), 115.1\left(\mathrm{C}-2^{\prime}\right), 119.8\left(\mathrm{C}-5^{\prime}\right), 163.3(\mathrm{C}-2)$, $181.1(\mathrm{C}=\mathrm{O}), 127.9,129.5,129.8,131.2$ (aromatic carbons); IR $(\mathrm{KBr}): v=3216(\mathrm{NH}), 1668$ $(\mathrm{C}=\mathrm{O}), 1569(\mathrm{C}=\mathrm{N}), 1336,1145\left(\mathrm{SO}_{2}\right)$; Anal. Calcd. for $\mathrm{C}_{15} \mathrm{H}_{14} \mathrm{~N}_{2} \mathrm{O}_{3} \mathrm{~S}_{2}$ (334.41): C, 53.87; H, $4.22 ; \mathrm{N}, 8.38$. Found: $\mathrm{C}, 53.84 ; \mathrm{H}, 4.20 ; \mathrm{N}, 8.34$.

2-(4'-(p-Methylbenzoyl-1' $\boldsymbol{H}$-pyrrol-3'-sulfonylmethyl)-4,5-dihydrothiazole (8b). Yield 0.229 g (66\%); white solid; m. p. $158-160{ }^{\circ} \mathrm{C} ;{ }^{1} \mathrm{H}$ NMR (300 MHz, DMSO- $\left.d_{6}\right): \delta=2.51$ (s, $\left.3 \mathrm{H}, \mathrm{CH}_{3}\right)$, 3.39 (t, $J=8.1 \mathrm{~Hz}, 2 \mathrm{H}, \mathrm{H}-5), 3.82$ (t, $J=8.1 \mathrm{~Hz}, 2 \mathrm{H}, \mathrm{H}-4), 4.25$ (s, 2H, $\left.\mathrm{SO}_{2}-\mathrm{CH}_{2}\right), 6.49(\mathrm{~s}, 1 \mathrm{H}$, $\left.\mathrm{H}-2^{\prime}\right), 6.81$ (s, 1H, H-5'), 7.36-7.59 (m, 4H, Ar-H), 9.18 (bs, $\left.1 \mathrm{H}, \mathrm{NH}\right) ;{ }^{13} \mathrm{C}$ NMR $(300 \mathrm{MHz}$, DMSO- $\left.d_{6}\right): \delta=24.2\left(\mathrm{CH}_{3}\right), 37.8(\mathrm{C}-5), 52.9(\mathrm{C}-4), 56.4\left(\mathrm{SO}_{2}-\mathrm{CH}_{2}\right), 102.9\left(\mathrm{C}-4^{\prime}\right), 103.6\left(\mathrm{C}-3^{\prime}\right)$, $115.7\left(\mathrm{C}-2^{\prime}\right), 118.9\left(\mathrm{C}-5^{\prime}\right), 161.8(\mathrm{C}-2), 182.4(\mathrm{C}=\mathrm{O}), 127.4,129.2,129.6,131.1$ (aromatic carbons); IR (KBr): $v=3214(\mathrm{NH}), 1663(\mathrm{C}=\mathrm{O}), 1564(\mathrm{C}=\mathrm{N}), 1331,1139\left(\mathrm{SO}_{2}\right)$; Anal. Calcd. for $\mathrm{C}_{16} \mathrm{H}_{16} \mathrm{~N}_{2} \mathrm{O}_{3} \mathrm{~S}_{2}$ (348.44): C, 55.15; H, 4.63; N, 8.04. Found: C, 55.11; H, 4.61; N, 8.01.

2-(4'-(p-Chlorobenzoyl-1' $\boldsymbol{H}$-pyrrol-3'-sulfonylmethyl)-4,5-dihydrothiazole (8c). Yield 0.254 g (69\%); white solid; m. p. $193-195{ }^{\circ} \mathrm{C} ;{ }^{1} \mathrm{H}$ NMR (300 MHz, DMSO- $\left.d_{6}\right): \delta=3.42$ (t, $J=8.3 \mathrm{~Hz}$, $2 \mathrm{H}, \mathrm{H}-5), 3.87$ (t, $J=8.3 \mathrm{~Hz}, 2 \mathrm{H}, \mathrm{H}-4), 4.29$ (s, 2H, SO $2_{2}-\mathrm{CH}_{2}$ ), 6.51 (s, $\left.1 \mathrm{H}, \mathrm{H}-2^{\prime}\right), 6.89$ (s, $1 \mathrm{H}$, $\left.\mathrm{H}-5^{\prime}\right)$; 7.44-7.67 (m, 4H, Ar-H), 9.21 (bs, $\left.1 \mathrm{H}, \mathrm{NH}\right) ;{ }^{13} \mathrm{C}$ NMR (300 MHz, DMSO- $\left.d_{6}\right): \delta=38.8$ (C-5), 53.9 (C-4), $55.1\left(\mathrm{SO}_{2}-\mathrm{CH}_{2}\right), 101.4\left(\mathrm{C}-4^{\prime}\right), 104.2$ (C-3'), 115.6 (C-2'), 119.4 (C-5'), 163.2 $(\mathrm{C}-2), 181.1(\mathrm{C}=\mathrm{O}), 129.1,129.8,131.5,133.4$ (aromatic carbons); IR $(\mathrm{KBr}): v=3219(\mathrm{NH})$, $1673(\mathrm{C}=\mathrm{O}), 1566(\mathrm{C}=\mathrm{N}), 1338,1132\left(\mathrm{SO}_{2}\right)$; Anal. Calcd. for $\mathrm{C}_{15} \mathrm{H}_{13} \mathrm{ClN}_{2} \mathrm{O}_{3} \mathrm{~S}_{2}$ (368.86): $\mathrm{C}$, 48.84; H, 3.55; N, 7.59. Found: C, 48.72; H, 3.52; N, 7.65.

\section{Antimicrobial activity}

\section{Chemistry}

The compounds 5-8 were dissolved in DMSO at different concentrations of 100, $200 \& 800$ $\mu \mathrm{g} / \mathrm{mL}$.

\section{Cells}

Bacterial strains Staphylococcus aureus, Bacillus subtilis, Klebsiella pneumoniae, Proteus vulgaris and fungi Aspergillus niger, Fusarium solani \& Curvularia lunata were obtained from NCIM, Pune, India. 


\section{Antibacterial and antifungal assays}

Preliminary antimicrobial activities of compounds 5-8 were tested by agar disc-diffusion method. Sterile filter paper discs (6 mm diameter) moistened with the test compound solution in DMSO of specific concentration $100 \mu \mathrm{g}$ and $200 \mu \mathrm{g}$ /disc were carefully placed on the agar culture plates that had been previously inoculated separately with the microorganisms. The plates were incubated at $37^{\circ} \mathrm{C}$ and the diameter of the growth inhibition zones were measured after $24 \mathrm{~h}$. in case of bacteria and after $48 \mathrm{~h}$. in case of fungi.

The MICs of the compound assays were carried out using microdilution susceptibility method. Chloramphenicol was used as reference antibacterial agent. Ketoconazole was used as reference antifungal agent. The test compounds, Chloramphenicol and Ketoconazole were dissolved in DMSO at concentration of $800 \mu \mathrm{g} / \mathrm{mL}$. The twofold dilution of the solution was prepared (400, $200,100, \ldots, 6.25 \mu \mathrm{g} / \mathrm{mL})$. The microorganism suspensions were incubated at $36^{\circ} \mathrm{C}$ for 24 and $48 \mathrm{~h}$. for bacteria and fungi, respectively. The minimum inhibitory concentrations of the compounds were recorded as the lowest concentration of each chemical compounds in the tubes with no turbidity (i.e. no growth) of inoculated bacteria/fungi.

\section{Acknowledgements}

The authors are thankful to UGC, New Delhi, India for financial assistance under major research project. One of the authors K. Mahesh is thankful to CSIR, New Delhi, India for the sanction of Senior Research Fellowship.

\section{References}

1. (a) Wang, C. C. C.; Derven, P. B. J. Am. Chem. Soc. 2001, 123, 8657. (b) Wellenzohn, B.; Flader, W.; Winger, R. H.; Hallabruker, A.; Mayer, E.; Liedl, K. R. J. Am. Chem. Soc. 2001, 123, 5044. (c) Sharma, S. K.; Tandon, M.; Lown, J. W. J. Org. Chem. 2001, 66, 1030. (d) Wurtz, N. R.; Turner, J. M.; Baird, E. E.; Dervan, P. B. Fmoc. Org. Lett. 2001, 3, 1201. (e) Dyatkina, N. B.; Roberts, C.D.; Keicher, J. D.; Dai, Y.; Nadherny, J. P.; Zhang, W.; Schmitz, U.; Kongpachith, A.; Fung, K.; Nokikov, A.A.; Lou, L.; Velligan, M.; Khorlin, A. A.; Chen, M. S. J. Med. Chem. 2002, 45, 805.

2. Leffler, M.; Adams, R.; T. J. Am. Chem. Soc. 1937, 59, 2252.

3. (a) Jin, Z. Nat. Prod. Rep. 2003, 20, 584. (b) Lewis, J. R. Nat. Prod. Rep. 2002, 19, 223. (c) Linder, J.; Moody, C. J. Chem. Commun. 2007, 1508. (d) Jin, Z. Nat. Prod. Rep. 2006, 23, 464. (e) Manju, S. L.; Asha. S.; Reji, T. F. A. F. Rajasekharan. K. N. ARKIVOC 2008, (xv), 288. (f) Yeh, V. S. C. Tetrahedron 2004, 11995. (g) Li, Y. M.; Milne, J. C.; Madison, L. L.; Kolter, R.; Walsh, C. T. Science 1996, 1188. 
4. (a) Shiraish, H.; Nishitani, T.; Nishihara, T.; Sakaguchi, S.; Ishii.Y. Tetrahedron 1999, 55, 13957. (b) Zelikin, A.; Shastri, V. R.; Langer. R. J. Org. Chem. 1999, 64, 3379. (c) Liu, J. H.; Chan, H. W.; Wong, H. N. C. J. Org. Chem. 2000, 65, 3274.

5. (a) Van Leusen, A. M.; Siderius, H.; Hoogenboom, B. E.; Van Leusen. D. Tetrahedron Lett. 1972, 5337. (b) Pavri, N. P.; Trudell, M. L. J. Org. Chem. 1977, 62, 2649.

6. Padmavathi, V.; Jagnan Mohan Reddy, B.; Rajagopal Sarma, M.; Thriveni. P. J. Chem. Res. (s) 2004, 79.

7. (a) Wipf, P.; Miller. C. P. Tetrahedron Lett. 1992, 33, 6267. (b) Phillips, A. J.; Uto, Y.; Wipf, P.; Reno, M. J.; Williams. D. R. Org. Lett. 2000, 2, 1165.

8. Meyers, A. I.; Slade, J. J. Org. Chem. 1980, 45, 2785.

9. (a) Vorbruggen, H.; Krolikiewicz. K. Tetrahedron 1993, 49, 9353. (b) Cwik, A.; Hell, Z.; Hegedus, A.; Finta, Z.; Horvath, Z. Tetrahedron Lett. 2002, 43, 3985.

10. (a) Panek, J. S.; Masse,C. E. J. Org. Chem. 1998, 63, 2382. (b) Kamata, K.; Agata, I.; Meyers. A. I. J. Org. Chem. 1998, 63, 3113.

11. Oussaid, B.; Berlan, J.; Soufiaoui, M.; Garrigues. B. Synth. Commun. 1995, 25, 659.

12. (a) Schumacher, D. P.; Clark, J. E.; Murphy, B. L.; Fischer. P. A. J. Org. Chem. 1990, 55, 5291. (b) Bower, J. F.; Martin, C. J.; Rawson, D. J.; Slawin, A. M. Z.; Williams. J. M. J. J. Chem. Soc. Perkin Trans. 1, 1996, 333;

13. (a) North, M.; Pattenden. G. Tetrahedron 1990, 46, 8267. (b) Charette, A. B.; Chua. P. J. Org. Chem. 1998, 63, 908. (c) Busacca, C. A. ; Dong, Y.; Spinelli. E. M. Tetrahedron Lett. 1996, 37, 2935.

14. (a) Wenker, H. J. Am. Chem. Soc. 1935, 57, 1079. (b) Nishio, T. Tetrahedron Lett. 1995, 36, 6113. (c) Wipf, P.; Fritch, P. C. Tetrahedron Lett. 1994, 35, 5397. (d) Lafargue, P.; Guenot, P.; Lellouche, J. P. Synlett. 1995, 171. (e) Mahler, S. G.; Serra, G. L.; Antonow, D.; Manta, E. Tetrahedron Lett. 2001, 42, 8143.

15. (a) Wipf, P.; Miller, C. P.; Venkataraman, S.; Fritch, P. C. Tetrahedron Lett. 1995, 36, 6395.

(b) Wipf, P.; Fritch. P. C. J. Am. Chem. Soc. 1996, 118, 12358. (c) Wipf, A. P.; Uto, Y. J. Org. Chem. 2000, 65, 1037.

16. White, J. D.; Kim, T. S.; Nambu, M. J. Am. Chem. Soc. 1995, 117, 5612.

17. Peiwen, Z. J.; Blubaum, E.; Christopher, T. B.; Nicholas, R. N. Tetrahedron Lett. 1997, 38, 7019.

18. Vincent, J. C.; Vincent, H. W. Proc. Soc. Exp. Biol. Med, 1944, 55, 162.

19. Bhaskar Reddy, D.; Chandrasekhar Babu, N.; Padmavathi, V.; Sumathi, R. P. Synthesis 1999, 491. 